\title{
Prevalence, Co-Occurrence and Correlates of Unhealthy Behaviors: Secondary Analysis of Survey of Young People In Egypt "SYPE", 2014
}

\author{
Sabra M. Ahmed and Mahmoud A. Abdel-Aty \\ Public Health \& Community Medicine Dept., Assiut University, Egypt
}

Received: March $2017 \quad$ Accepted : May 2017

\begin{abstract}
Objectives: The present study aimed to identify the prevalence, and socio-demographic correlates of the isolated and simultaneous presence of health risk behaviors among youth aged 13 - 35 years in Egypt. Methods: The Survey of Young People in Egypt (SYPE), was conducted in 2014. This survey included 10,916 youth representing total Egypt. Selection of non-communicable diseases (NCDs) health risk behaviors and their explanatory variables of youth aged 13-35 years were used for secondary and advanced analysis. Results: The health risk behaviors with the highest prevalence were inadequate fruits and vegetable intake $(89.7 \%)$, inadequate physical activity $(49 \%)$, excess salt intake (44.2\%), and smoking (13.2\%). Eighty percent (80\%) of youth had two or more simultaneous non-communicable diseases (NCDs) risk behaviors. By applying logistic regression analysis, age (tend to accumulate as adolescents grow older) and females were statistically associated with co-occurrence of health risk behaviors. Lower Egypt was the least geographic region of aggregation of risk behaviors. Conclusion and recommendations: A high prevalence of NCDs health risk behaviors among youth was found in Egypt, both isolated and simultaneously which could expect a significant increase in NCDs in the near future. Multi-sectoral integrated approach to encourage people to adopt healthy behaviors on individual-and population-level is recommended.
\end{abstract}

Key words: Risk behavior, Youth, SYPE, Egypt.

Corresponding author:. Sabra M. Ahmed E-mail: sabraa16@gmail.com

\section{Introduction:}

Lifestyle is one of the major determinants of health. Modifiable life style risk behaviors such as smoking, unhealthy diet, physical inactivity and alcohol misuse are the leading causes of these major NCDs worldwide. ${ }^{1}$ Engaging in multiple risk behaviors is associated with greater risk of chronic disease and mortality. $^{2}$ In Egypt, the NCDs are estimated to account for $85 \%$ of total deaths (mainly CVDs; $46 \%$ ). ${ }^{3}$

Many behaviors are established during adolescence and continue into adulthood. ${ }^{4}$ The prevalence of NCDs is related to unhealthy behaviors and practices typically initiated in adolescence, yet they are a natural partner for preventing NCDs. ${ }^{5}$

Health promotion activities among adolescents and young adults should be carried out, aiming at facilitating their adoption of health-promoting behaviors and eventually reducing chronic morbidity and premature mortality at a later age. ${ }^{1}$ Greater effort are being targeted at multiple health behavior change (MHBC). Analyses of aggregation of multiple behaviors may help future health promotion programs. ${ }^{6}$ The present study aimed to identify the prevalence and socio-demographic correlates of single and combined non- 
communicable diseases (NCDs) (mainly cardiovascular (CVDs) health risk behaviors among youth aged $13-35$ years in Egypt.

\section{Methods:}

Survey of Young People in Egypt (SYPE), 2014 was conducted by the Central Agency for Public Mobilization and Statistics (CAPMAS) and Population Council. Data from population-based household survey (SYPE), 2014 were (down loaded from internet) used in this study. The SYPE adopted a multistage stratified cluster sampling all over Egypt to select 10,916 eligible young people aged 13-35 years. An interview questionnaire was used to collect detailed data related to education, employment, migration, health, risky behaviors, violence, family formation, social issues, and civic and political participation. Selection of the health risk behaviors and their explanatory variables of youth aged 13-35 years for secondary and advanced analysis was used in this study. Details of the study methodology have been published elsewhere. $^{7}$

Recoding of the variables so that the responses are changed into zero and one (one for doing the risky behavior and zero for not doing the behavior). To identify the simultaneous presence of risky behaviors, summation of the related variables for each respondent was performed.

Definition of the variables: Smoking: SYPE, $2014^{7}$ considered respondent ever smoker if he /she is currently smoking, currently smoke occasionally, tried some puffs, or smokes tobacco products other than cigarettes daily (Q4207). The same definition was followed by this study. Alcohol consumption and drug use: if the respondent tried any alcoholic drinks (beer or wine) (Q4215) or if the respondent has experimented with any drugs before (Q4221). Physical inactivity: this included a series of questions asking respondents about their daily physical activities, including biking and walking, going to a gym, playing sports at home or in club or in youth center, playing football on the street or physical work on the job (Q4250). SYPE, $2014^{7}$ considered respondents who do not engage in any daily physical activity as physically inactive whereas those engaged in one or more of these physical activities were considered physically active. The same classification was followed by this study. Internet hours per day: how many hours would the respondent spends online per day (Q5903). Similar to other studies ${ }^{8,9}$, the adolescent was considered at risk when he/she reported two or more hours on line every day. Frequency of intake of different food items: last week, how often did the respondent eat sweets, fast foods, soft drinks, fruits, fresh or cooked vegetable (Q4199). The answers were none, $1-3$ times and > 3 times. Recoding of the variables were done so that the first two answers became one category $(<4$ times/ week). Comparison between both categories $(<4$ times and $\geq$ 4 times /week) was performed. Excess salt: does the respondent like his/her food very salty? (Q4197) and how often did the respondent eat pickled vegetables last week (Q4199). Wealth level: SYPE, 2014 constructed a wealth score using factor analysis based on household-asset ownership and housing characteristics. Based on their wealth scores, households were divided into wealth quintiles. ${ }^{7}$ The same wealth level was used in this study with recoding of the first and second quintiles to form the high level and the third level constituted the middle level and recoding of the fourth and fifth quintiles to form the low wealth level. Education: Recoding of the primary and preparatory education was done to form the basic education. Also, recoding of secondary and higher education to form one category (secondary and higher). 
Statistical analysis: The prevalence of isolated and simultaneous behaviors was performed. The proportion differences between categories were evaluated by a Chi square test. Multivariate logistic regression analysis was performed for significant variables. SPSS, version 20 were used for data analysis. $\mathrm{P}$ value less than 0.05 was considered significant.

\section{Results}

Table (1) shows mainly NCDs modifiable risk behaviors; $13.2 \%$ are ever smokers $(11.4 \%$ are current smokers; data are not shown), $2.1 \%$ tried alcohol or drugs in the past years, about half of the respondents $(49 \%)$ are physically inactive, $11.8 \%$ used internet two hours or more per day and 44.2 and $9.2 \%$ consume excess salts and sweet in their diet. Smokers and those who use alcohol or drugs were more likely to be males, older, residing in urban areas and urban governorates, had basic education and employed respondents. The highest rates of smokers were observed among employed respondents $(32.7 \%)$ and males (28. 1\%). The highest rates of physical inactivity were observed among females $(61.5 \%)$ and residents of informal areas (60. 9\%). Those who used internet $\geq 2$ hours per day were more likely to be males, younger, residing in urban areas and Urban governorates, of higher wealth level, and had secondary or higher education. The highest rates were observed among Urban governorates $(24.5 \%)$ and urban areas (21. 2\%). Those who took excess salt were more likely to be residing in informal areas and urban governorates. Those who ate excess sweet were more likely to be females, younger, residing in urban areas and Urban governorates, of higher wealth level, had secondary or higher education and unemployed respondents.

Table (2) shows mainly eating habits: about $90 \%$ are consuming fruits and vegetables less than 4 times per week. They were more likely to be residing in urban areas and urban governorates, of middle wealth level and illiterate respondents. Those who took excess soft drinks (11.3\%) and fast foods $(8.3 \%)$ were more likely to be males, older, residing in urban areas and urban governorates, higher wealth level and had secondary and higher education. The highest rates were observed among urban governorates and urban areas. This table also shows that those with higher $(79.9 \%)$ simultaneous NCDs (2 9) risky behaviors were more likely to be residing in informal areas (85.7\%), urban governorates $(86 \%)$, and female gender $(81.9 \%)$ and of older age $(81.1 \%)$.

Table (3) showed that about 19\%, $41 \%$ and $25 \%$ of respondents had one, two or three simultaneous NCDs risky behaviors. Inadequate fruits \& vegetable intake and physical inactivity were common combination (data not shown).There was a difference between genders; females had 2 or even 3 combined risk behaviors higher than males while males had four and more combined risk behaviors higher than females. Also, two and more risk factors were higher in females $(81.1 \%)$ than males $(78.6 \%)$. Eighty percent had two or more multiple NCDs risk behaviors, $39.1 \%$ had three or more and on average $2.3 \pm 1.1$ (range: $0-9$ ) and only $0.9 \%$ had none

Table (4) showed by applying logistic regression analysis that, residing in Lower Egypt and urban or rural but not informal areas, younger, male gender and those of middle and high wealth level are at lower risk of developing high $(2-9)$ simultaneous NCDs risk behaviors. 
Table (1): Percent distribution of NCDs/CVDs risk behaviors by youth characteristics in Egypt, SYPE, 2014.

\begin{tabular}{|c|c|c|c|c|c|c|}
\hline $\begin{array}{c}\text { Youth } \\
\text { Characteristics }\end{array}$ & Smoking & $\begin{array}{l}\text { Alcohol or } \\
\text { drug } \\
\text { abuse }\end{array}$ & $\begin{array}{l}\text { Physical } \\
\text { Inactivity }\end{array}$ & $\begin{array}{c}\text { Internet } \geq \\
2 \\
\text { hours/day }\end{array}$ & $\begin{array}{c}\text { Excess } \\
\text { salt } \\
\geq 4 \mathrm{x} / \mathrm{wk}\end{array}$ & $\begin{array}{c}\text { Excess } \\
\text { sweet } \\
\geq 4 \mathrm{x} / \mathrm{wk}\end{array}$ \\
\hline Gender: - Male & 28.1 & 4.3 & 34.6 & 15.6 & 43.7 & 8.4 \\
\hline -Female & 0.2 & 0.1 & 61.5 & 8.5 & 44.7 & 9.9 \\
\hline $\mathrm{P}$ value & $<0.001$ & $<0.001$ & $<0.001$ & $<0.001$ & 0.301 & 0.005 \\
\hline \multicolumn{7}{|l|}{ Age: } \\
\hline - $13-24$ years & 9.9 & 1.7 & 44.7 & 9.7 & 44.7 & 11.2 \\
\hline$-25-35$ years & 17.7 & 2.6 & 55.0 & 5.7 & 43.6 & 6.5 \\
\hline \multicolumn{2}{|l|}{$\mathrm{P}$ value } & 0.002 & $<0.001$ & $<0.001$ & 0.244 & $<0.001$ \\
\hline \multicolumn{7}{|l|}{ Residence: } \\
\hline - Urban & 15.0 & 3.0 & 47.9 & 21.2 & 46.4 & 13.8 \\
\hline - Rural & 12.5 & 1.6 & 47.5 & 6.6 & 42.0 & 6.8 \\
\hline - Informal & 11.7 & 2.0 & 60.9 & 14.1 & 50.7 & 9.7 \\
\hline $\mathrm{P}$ value & 0.001 & $<0.001$ & $<0.001$ & $<0.001$ & $<0.001$ & $<0.001$ \\
\hline \multicolumn{7}{|l|}{ Region: } \\
\hline - Urban gov. & 17.2 & 3.9 & 46.3 & 24.5 & 50.7 & 16.3 \\
\hline - Lower Egypt & 11.1 & 1.3 & 48.3 & 10.6 & 43.1 & 9.3 \\
\hline - Upper Egypt & 14.7 & 1.7 & 48.0 & 6.6 & 43.5 & 5.7 \\
\hline - Frontier gov. & 9.8 & 2.8 & & 7.9 & 38.0 & 5.8 \\
\hline P value & $<0.001$ & $<0.001$ & $<0.001$ & $<0.001$ & $<0.001$ & $<0.001$ \\
\hline \multicolumn{7}{|l|}{ Wealth level: } \\
\hline - Low & 15.0 & 2.3 & 50.4 & 2.1 & 42.8 & 5.2 \\
\hline - Middle & 13.1 & 2.1 & 50.2 & 4.6 & 44.4 & 8.5 \\
\hline - High & 11.7 & 1.8 & 47.3 & 14.4 & 45.3 & 12.8 \\
\hline $\mathrm{P}$ value & $<0.001$ & 0.251 & 0.006 & $<0.001$ & 0.067 & 0.001 \\
\hline \multicolumn{7}{|l|}{ Education } \\
\hline - Illiterate & 10.3 & 1.3 & 59.7 & 0.0 & 42.6 & 3.8 \\
\hline - Basic & 16.0 & 3.1 & 48.6 & 3.3 & 45.4 & 7.3 \\
\hline - 2ry or higher & 12.7 & 1.9 & 47.3 & 16.7 & 44.1 & 10.8 \\
\hline $\mathrm{P}$ value & $<0.001$ & $<0.001$ & 0.006 & $<0.001$ & 0.263 & $<0.001$ \\
\hline \multicolumn{7}{|l|}{ Employment: } \\
\hline - Employed & 32.7 & 4.9 & 36.9 & 11.2 & 43.8 & 6.7 \\
\hline - Unemployed & 4.4 & 0.8 & 54.4 & 12.1 & 44.4 & 10.3 \\
\hline $\mathrm{P}$ value & $<0.001$ & $<0.001$ & $<0.001$ & 0.194 & 0.531 & $<0.001$ \\
\hline Total & $\begin{array}{r}1437 \\
(13.2)\end{array}$ & $\begin{array}{r}222 \\
(2.1)\end{array}$ & $\begin{array}{r}5341 \\
(49.0)\end{array}$ & $\begin{array}{r}1289 \\
(11.8)\end{array}$ & $\begin{array}{r}4820 \\
(44.2)\end{array}$ & $\begin{array}{l}1005 \\
(9.2)\end{array}$ \\
\hline
\end{tabular}


Table (2): Percent distribution of some dietary and total simultaneous risk behaviors by youth characteristics in Egypt, SYPE, 2014.

\begin{tabular}{|c|c|c|c|c|c|}
\hline \multirow[b]{2}{*}{ Youth characteristics } & \multirow{2}{*}{$\begin{array}{l}\text { Fruits/ veg. } \\
<4 \text { times } \\
\text { /week }\end{array}$} & \multirow{2}{*}{$\begin{array}{l}\text { Soft drinks } \\
\geq 4 \text { times } \\
\text { /week }\end{array}$} & \multirow{2}{*}{$\begin{array}{l}\text { Fast foods } \\
\geq 4 \text { times } \\
\text { /week }\end{array}$} & \multicolumn{2}{|c|}{$\begin{array}{l}\text { Total simultaneous } \\
\text { risk behaviors }\end{array}$} \\
\hline & & & & $0-1$ risks & $2-9$ risks \\
\hline $\begin{array}{l}\text { Gender: } \\
\text { - Male } \\
\text { - Female }\end{array}$ & $\begin{array}{r}90.0 \\
89.5 \\
\end{array}$ & $\begin{array}{l}12.7 \\
10.1 \\
\end{array}$ & $\begin{array}{r}10.6 \\
6.4 \\
\end{array}$ & $\begin{array}{l}21.5 \\
18.1 \\
\end{array}$ & $\begin{array}{l}78.5 \\
81.9\end{array}$ \\
\hline $\mathrm{P}$ value & 0.383 & $<0.001$ & $<0.001$ & \multicolumn{2}{|c|}{$<0.001$} \\
\hline $\begin{array}{l}\text { Age: } \\
\begin{array}{l}-13-24 \text { years } \\
-25-35 \text { years }\end{array}\end{array}$ & $\begin{array}{r}89.8 \\
89.5 \\
\end{array}$ & $\begin{array}{r}13.2 \\
8.7 \\
\end{array}$ & $\begin{array}{r}10.0 \\
6.1 \\
\end{array}$ & $\begin{array}{l}21.4 \\
18.9 \\
\end{array}$ & $\begin{array}{l}78.6 \\
81.1\end{array}$ \\
\hline $\mathrm{P}$ value & 0.586 & $<0.001$ & $<0.001$ & \multicolumn{2}{|c|}{0.002} \\
\hline $\begin{array}{l}\text { Residence: } \\
\text { - Urban } \\
\text { - Rural } \\
\text { - Informal }\end{array}$ & $\begin{array}{l}88.2 \\
92.1 \\
80.0 \\
\end{array}$ & $\begin{array}{r}16.7 \\
8.7 \\
10.3 \\
\end{array}$ & $\begin{array}{r}12.7 \\
6.1 \\
8.1 \\
\end{array}$ & $\begin{array}{l}15.8 \\
23.2 \\
14.3 \\
\end{array}$ & $\begin{array}{l}84.2 \\
76.8 \\
85.7\end{array}$ \\
\hline $\mathrm{P}$ value & $<0.001$ & $<0.001$ & $<0.001$ & \multicolumn{2}{|c|}{$<0.001$} \\
\hline $\begin{array}{l}\text { Region: } \\
\text { - Urban gov. } \\
\text { - Lower Egypt } \\
\text { - Upper Egypt } \\
\text { - Frontier gov. }\end{array}$ & $\begin{array}{l}84.5 \\
82.2 \\
88.4 \\
89.7\end{array}$ & $\begin{array}{r}20.0 \\
11.1 \\
7.9 \\
4.8\end{array}$ & $\begin{array}{r}15.3 \\
7.8 \\
5.4 \\
5.9\end{array}$ & $\begin{array}{l}14.0 \\
23.1 \\
20.0 \\
18.3\end{array}$ & $\begin{array}{l}86.0 \\
76.9 \\
80.0 \\
81.7\end{array}$ \\
\hline $\mathrm{P}$ value & $<0.001$ & $<0.001$ & $<0.001$ & \multicolumn{2}{|c|}{$<0.001$} \\
\hline $\begin{array}{l}\text { Wealth level: } \\
\text { - Low } \\
\text { - Middle } \\
\text { - High }\end{array}$ & $\begin{array}{r}89.5 \\
85.5 \\
81.5 \\
\end{array}$ & $\begin{array}{r}6.1 \\
11.0 \\
15.7 \\
\end{array}$ & $\begin{array}{r}4.8 \\
8.0 \\
11.4 \\
\end{array}$ & $\begin{array}{l}21.7 \\
20.7 \\
18.4\end{array}$ & $\begin{array}{l}78.3 \\
79.3 \\
81.6\end{array}$ \\
\hline $\mathrm{P}$ value & $<0.001$ & $<0.001$ & $<0.001$ & \multicolumn{2}{|c|}{$<0.001$} \\
\hline $\begin{array}{l}\text { Education } \\
\text { - Illiterate } \\
\text { - Basic } \\
\text { - 2ry or higher }\end{array}$ & $\begin{array}{r}89.4 \\
88.2 \\
83.5 \\
\end{array}$ & $\begin{array}{r}4.1 \\
8.7 \\
13.4 \\
\end{array}$ & $\begin{array}{r}2.4 \\
6.4 \\
10.0 \\
\end{array}$ & $\begin{array}{l}20.6 \\
21.7 \\
19.4 \\
\end{array}$ & $\begin{array}{l}79.4 \\
78.3 \\
80.6 \\
\end{array}$ \\
\hline $\mathrm{P}$ value & $<0.001$ & $<0.001$ & $<0.001$ & \multicolumn{2}{|c|}{0.059} \\
\hline $\begin{array}{l}\text { Employment: } \\
\text { - Employed } \\
\text { - Unemployed }\end{array}$ & $\begin{array}{r}89.0 \\
90.0\end{array}$ & $\begin{array}{r}11.1 \\
11.4\end{array}$ & $\begin{array}{r}9.5 \\
7.8 \\
\end{array}$ & $\begin{array}{l}21.2 \\
19.6\end{array}$ & $\begin{array}{l}78.8 \\
80.4\end{array}$ \\
\hline 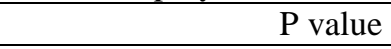 & 0.107 & 0.711 & 0.005 & \multicolumn{2}{|c|}{0.052} \\
\hline Total & $\begin{array}{l}9780 \\
(89.7) \\
\end{array}$ & $\begin{array}{c}1233 \\
(11.3) \\
\end{array}$ & $\begin{array}{l}909 \\
(8.3) \\
\end{array}$ & $\begin{array}{c}2158 \\
(20.1) \\
\end{array}$ & $\begin{array}{r}8597 \\
(79.9) \\
\end{array}$ \\
\hline
\end{tabular}


Table (3): Prevalence of simultaneous NCDs risky behaviors among youth in Egypt, SYPE, 2014.

\begin{tabular}{|c|c|c|c|c|}
\hline \multirow{2}{*}{$\begin{array}{c}\text { No. of risky } \\
\text { behaviors }\end{array}$} & \multicolumn{2}{|c|}{ Gender } & \multirow{2}{*}{$\begin{array}{c}\text { Total* } \\
\text { No. }(\%)\end{array}$} & \multirow{2}{*}{$\begin{array}{c}\text { Descending } \\
\text { cumulative } \\
\text { percent }\end{array}$} \\
\hline & $\begin{array}{c}\text { Male } \\
\text { No. }(\%) \\
\end{array}$ & $\begin{array}{c}\text { Female } \\
\text { No. }(\%)\end{array}$ & & \\
\hline 0 & $48(1.0)$ & $52(0.9)$ & $100(0.9)$ & 100.0 \\
\hline 1 & $1018(20.4)$ & $1040(18.0)$ & $2058(19.1)$ & 99.1 \\
\hline 2 & $1808(36.2)$ & $2600(45.1)$ & $4408(41.0)$ & 80.0 \\
\hline 3 & $1214(24.3)$ & $1512(26.2)$ & $2726(25.3)$ & 39.1 \\
\hline 4 & $584(11.7)$ & $340(5.9)$ & $924(8.8)$ & 13.8 \\
\hline 5 & $213(4.3)$ & $158(2.7)$ & $371(3.4)$ & 5.0 \\
\hline 6 & $88(1.8)$ & $51(0.9)$ & $139(1.3)$ & 1.6 \\
\hline 7 & $18(0.3)$ & $11(0.2)$ & $29(0.3)$ & 0.3 \\
\hline Total & $4991(100.0)$ & $5764(100.0)$ & $10755(100.0)$ & \\
\hline
\end{tabular}

$*$ Mean $\pm S D=2.3 \pm 1.1$

Table (4): Logistic regression analysis for variables related to simultaneous NCDs risk behaviors among youth in Egypt, SYPE, 2014.

\begin{tabular}{|c|c|c|}
\hline Characteristics & OR $(95 \%$ CI $)$ & Significance \\
\hline $\begin{array}{l}\text { Region: } \\
\text { - Urban gov. } \\
\text { - Lower Egypt } \\
\text { - Upper Egypt } \\
\text { - Frontier gov. }\end{array}$ & $\begin{array}{r}1 \text { (reference) } \\
\mathbf{0 . 7 3 2}(\mathbf{0 . 6 0 5 - 0 . 8 8 5})^{*} \\
1.013(0.895-1.395) \\
1.113(0.831-1.233)\end{array}$ & $\begin{array}{l}<0.001 \\
<0.001 \\
0.907 \\
0.626\end{array}$ \\
\hline $\begin{array}{l}\text { Gender: - } \\
\text { - Female } \\
\text { - Male }\end{array}$ & 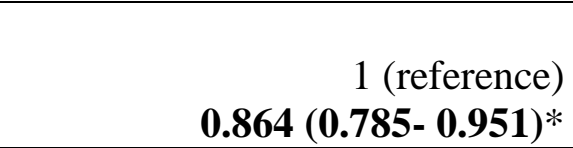 & 0.003 \\
\hline $\begin{array}{l}\text { Age: } \\
\text { - Older }(25-35) \\
\text { - Younger }(13-24)\end{array}$ & $\begin{array}{r}1 \text { (reference) } \\
\mathbf{0 . 8 1 5}(\mathbf{0 . 7 3 9 - 0 . 8 9 9 )} *\end{array}$ & $<0.001$ \\
\hline $\begin{array}{l}\text { Residency: } \\
\text { - Informal } \\
\text { - Rural } \\
\text { - Urban }\end{array}$ & $\begin{array}{r}1 \text { (reference) } \\
\mathbf{0 . 7 4 5}(\mathbf{0 . 6 1 3}-\mathbf{0 . 9 0 4 )} * \\
\mathbf{0 . 6 4 1}(\mathbf{0 . 5 4 2}-\mathbf{0 . 7 5 9}) *\end{array}$ & $\begin{array}{l}<0.001 \\
0.003 \\
<0.001\end{array}$ \\
\hline $\begin{array}{l}\text { Wealth level: } \\
\text { - Low6 } \\
\text { - Middle } \\
\text { - High }\end{array}$ & 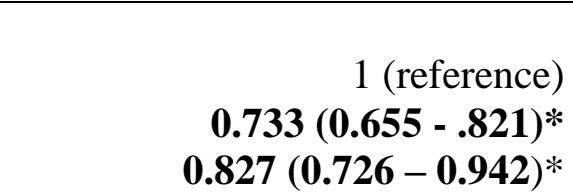 & $\begin{array}{c}<0.001 \\
<0.001 \\
0.004\end{array}$ \\
\hline
\end{tabular}

*Significant. 


\section{Discussion}

The comparisons between different studies are difficult and limited due to used different methodological procedures, types \& quantity, numbers of studied risky behaviors separately or combined, operational definition of characterizing risk factors, duration of exposures or habits; (daily, past week, typical week, week end, past month, current or ever user, ...etc.), different ages of studied samples, cultural/religious/legal background of the studied communities particularly substances uses and population-based or institution-based studies. $8,10-13$

The prevalence of current smoking observed in this study $(11.4 \%$; ever $13.2 \%$ much higher in males $28.1 \%$ than females $0.2 \%$ ) is low particularly in females compared to that observed in other countries. For example, in Bangladesh, $48 \%$ and $17 \%$ were using tobacco products by males and females adults aged 25-34 years and $28.5 \%$ for both. ${ }^{14}$ In Nepal, 39\% and $26 \%$ were using tobacco products by males and females adolescents aged 15-19 years. ${ }^{11}$ In Lebanon, the prevalence of current cigarette smoking was $19.2 \%$ and water pipe was $23 \%$ among private and public university students. ${ }^{15}$ In Canada (COMPASS study), current tobacco users among school adolescent students was $13.9 \% .{ }^{16}$ In university students in 23 low, middle and high-income countries the current tobacco use was $(12.7 \%){ }^{17}$ On the other hand, it is higher than that reported by adolescent students (14-19 years old) in Brazil $(7.6 \%){ }^{8}$ Globally, at least 1 in 10 younger adolescents (aged 13 - 15) uses tobacco. Several studies in different parts of the world reported higher prevalence of smoking among males than females and among older than younger adolescents. ${ }^{18}$
Alcohol /drug abuse in this study was $2.1 \%$. This is lower than that was reported in Lebanon, where $35.4 \%$ of private and public university students were currently consuming alcohol (48.5\% ever drinking). ${ }^{15}$ Also, in Brazil, alcohol consumption (having consumed alcohol in the last 30 days) among 14-19 years' adolescents was higher $(30.4 \%)^{8}$ than that reported by our study. Also, it is lower than that reported in Nepal, where about $50 \%$ male and $30 \%$ female adolescents aged 15-19 years were currently abusing one or other forms of substance. ${ }^{11}$ In Egypt alcohol and drug abuse are prohibited by legal, religious systems and are associated with stigma. The results of this study found that $49 \%$ of youth had inadequate physical activity; higher in females than males. This is consistent with that reported in Canada (COMPASS study) $(49.5 \%)^{16}$ and university students of lower and middle income countries $(48.6 \%)$, but higher than that reported in high income countries $(41.5 \%){ }^{17}$ The results of this study are much lower than that reported in a worldwide study for adolescents (1315 years old) from 105 countries, (80.3\%; boys are more active than girls). ${ }^{19}$ This is also lower than that reported in Brazil (65.1\%) among 14-19 years adolescent students ${ }^{(8)}$, and Nepal (56.5\% of male and $67.9 \%$ of female adolescents aged 15-19 years) ${ }^{11}$ and higher than that reported in Lebanon, where about 1 in 10 private and public university students played sports once daily. ${ }^{15}$ Also, in Bangladesh, $38 \%$ of adults aged 25 years and more had low physical activity level (<600METminutes/week). ${ }^{14}$ Also the prevalence of physical inactivity was $41.4 \%$ and reached $80.6 \%$ in Pakistan; higher in females than males among 17,928 undergraduate university students aged 16-30 years in 23 low, middle and highincome countries. The highest rate was

No. 3

July

2018 
found in Southeast Asian countries. ${ }^{17}$ WHO findings showed that fewer than 1 in every 4 adolescents globally meets the recommended guidelines for physical activity-60 minutes of moderate to vigorous physical activity daily. ${ }^{19}$

The results of this study found that inadequate fruits and vegetable intake among youth was $89.7 \%$. In Bangladesh, 93\% did not consume adequate fruit and vegetables ( $\geq 5$ servings / day) ${ }^{(14)}$. In university students in 23 low, middle and high-income countries, inadequate fruits and vegetables intake ( $<5$ servings/ day) was high $(81.8 \%)$ and to some extent lower than this study. ${ }^{17}$ In Canada (COMPASS study) inadequate fruits and vegetable intake among school adolescent students was lower than that reported by our study $74.3 \% .^{16}$ In Brazil, consumption of fruits and vegetables (<once a day) among 14-19 years' adolescents was higher than that reported by our study $(51.4 \%)^{(8)}$. In Lebanon, very few students consumed fruits (19\%), green salad (8.9\%), cooked vegetables $(3.4 \%)$ twice daily or more in the last 24 hours. ${ }^{15}$

Excess salt intake among youth in this study was $44.2 \%$, this figure is higher than that was reported in Nepal, where $26.2 \%$ of adolescents aged $15-19$ years were consuming large amount of salt per day (more than WHO recommendation). ${ }^{11}$

Internet use $\geq 2$ hours/ day in this study was $11.8 \%$ (higher in males and younger), lower than that reported in Lebanon by private and public university students who spent more than two hours / day for computer stay $(50.4 \%){ }^{15}$ It is also lower than that was reported in Canada (COMPASS study), where internet use $\geq 2$ hours / day among school adolescent students was $48.8 \% .^{16}$ In the (SYPE, 2010) conducted on $10 \quad-29$ years-old, internet use was not an everyday activity. Males used the internet about three times longer per day
(0.14 hour) than females. ${ }^{20}$ This low use may be explained by still high illiteracy/read \&write and even many youth did not complete mandatory basic education particularly among females and older youth, residing in rural areas and of lower wealth level. ${ }^{7}$ In this study, consumption of low-nutrient \& energydense food which are associated with overweight/obesity (obesogenic behaviors) as excess soft drinks $\geq 4$ times /week was $11.3 \%$, excess sweet was $9.2 \%$ ) and fast foods $\geq 4$ times /week was $8.3 \%$. It is lower than that was reported in Canada (COMPASS study) where dietary habits associated with overweight /obesity as excess beverage and sweet was $34.8 \%$, fast foods $\geq 1$ time per week was $67.5 \%$ among school adolescent students. ${ }^{16}$

The factors that shape patterns of behaviors such as social acceptance, religious values, culture, legislation and regulatory frameworks, may vary between different countries.

Combination of unhealthy behaviors: Engaging in multiple risk behaviors is associated with greater risk whether an additive or synergistic negative influence on chronic diseases and mortalities. ${ }^{2}$

As most of the existing evidence on the common NCD risk factors is based on analysis of a single factor at a time, there is a need to investigate the co-occurrence of the common NCD risk behaviors. ${ }^{21}$

In this study, $80 \%$ of youth $(13-35$ years) had two or more NCDs risk behaviors, $39.1 \%$ had three or more and on average $2.3 \pm 1.1$ (range: $0-9$ ) and only $0.9 \%$ had none. By using logistic regression analysis for unhealthy behaviors of NCDs $(2-9)$ according to demographic factors, it was observed that younger, male gender and those of middle and high wealth level are at lower risk of developing high (2-9) simultaneous NCDs risk behaviors.

In Southern Brazil ${ }^{9}$, only $6.5 \%$ of 3990 adolescents aged 14-15 years did not 
display any of the four risk behaviors analyzed. In other study in Brazil, about $10 \%$ of 4217 adolescents of high-school students enrolled in public schools, (1419 yrs old) were not exposed to health risk behaviors. ${ }^{8}$ The results of these studies were better than our results (0.9\%).

In USA, a recent study of the prevalence of five health-related behaviors among 395,343 BRFSS (Behavioral Risk Factor Surveillance System) respondents aged 21 years or older, only $1.4 \%$ of respondents engaged in none of the 5 behaviors $^{22}$ which is nearly similar to our results.

The very low prevalence of young people free from risk behaviors in this study $(0.9 \%)$ may be explained by high number of studied risk behaviors and also high combination of unhealthy risk behaviors.

The combination of two or more NCDs risk behaviors in adolescent sample were $58.5 \%$ in Brazil. $^{8} 48.2 \%$ in Southern Brazil $^{9}$ and $24.3 \%$ in $\mathrm{USA}^{22}$ which were lower than that of our results $(80 \%)$. The clustering continued to rise in adults to reach $52 \%$ in $\mathrm{USA}^{23}, 55 \%$ in the Netherlands $^{24}$, and $59 \%$ in Brazil $^{25}$ and increased markedly to reach $68 \%$ in England $^{26}$, and about $75 \%$ in Bangladesh. ${ }^{14}$ The combination of three or more NCDs risk behaviors were $12.4 \%$ in Southern Brazil $^{9}$, 35.4\% in $\mathrm{USA}^{22}$ and $38 \%$ in Bangladesh ${ }^{14}$ which is lower than our results $(39.1 \%)$.

In this study, there was a difference between genders; females had 2 or even 3 combined risk behaviors higher than males. Also, two and more risk behaviors were higher in females $(81.9 \%)$ than males $(78.5 \%$ ) (table 2) and by applying logistic regression analysis, male respondents were at lower risk of developing high $^{2-9}$ simultaneous NCDs risk behaviors. Inadequate fruits \& vegetable intake and physical inactivity were common combination (data not shown).
In Southern Brazil ${ }^{9}$, two and more risk behaviors were higher in females than males. Among males; smoking clustered with alcohol intake (very low in our study) and physical inactivity and among females; low fruit intake clustered with physical inactivity. In university students in 23 low, middle and high-income countries, low fruits \& vegetables intake and physical inactivity were aggregated $(40 \%)$ and higher in women than men. ${ }^{17}$

Older youth $(81.1 \%)$ was associated with multiple unhealthy behaviors of $\mathrm{NCDs}^{2-9}$ compared to younger $(78.6 \%)$ and this is supported by applying logistic regression analysis. This is consistent with other studies in Brazil ${ }^{8,9}$ and Bangladesh ${ }^{14}$ and low, middle and high-income countries. ${ }^{17}$ Clustering phenomenon in our sample was prominent with increasing age and female gender.

\section{Conclusion and Recommendations:}

The Egyptian youth are exposed to high single (with the exception of alcohol, and smoking among females) or simultaneous health risk behaviors particularly low fruit $\&$ vegetables intake and physical inactivity especially among females. Our findings suggest that Egypt could expect a significant increase in NCDs of the coming adult generations.

Clustering raises risk by more than a summation of risk behaviors which needs more elaboration in our community and further research is required to investigate the interrelationships of lifestyle risk behaviors.

Early integrating health promotion and multiple health behavior change interventions are needed before unhealthy habits become established to prevent accumulation of risk behaviors as youth mature and their future adverse health outcomes.

Creation of awareness and engagement of various stakeholders beyond health sector to encourage people to adopt

$\begin{array}{llll}\text { Vol. } 36 & \text { No. } 3 & \text { July } & 2018\end{array}$


healthy behaviors with an enabling environment and to develop/implement an appropriate policies and programs. Strict implementation of WHO Framework Convention on Tobacco Control (FCTC) among men. Surveillances of health behaviors and NCDS on standard comparable indicators on regular basis should be established.

\section{References:}

1. WHO (2014A): Global status report on non-communicable diseases 2014. 'Attaining the nine global noncommunicable diseases targets; a shared responsibility.

2. Myint PK, Luben RN, Wareham NJ, Bingham SA, KhawK. (2009): Combined Effect of health behaviors and risk of first ever stroke in 20,040 men and women over11years' follow-up in Norfolk cohort of European Prospective Investigation of Cancer (EPICNorfolk). BMJ; 338: b349. http://dx.doi.org/10.1136/bmj.b349.

3. WHO (2014B): Non-communicable diseases country profiles available at:

4. http://apps.who.int/iris/bitstream/1066 5/128038/1/9789241507509_engpdf.

[Accessed23March2015].

5. Paavola M, Vartiainen E, Haukkala A (2004): Smoking, alcohol use, and physical activity: a 13-year longitudinal study ranging from adolescence into adulthood. J Adolesc Health 2004, 35(3):238-244.

6. Baldwin W, Kaneda T, Amato L and Nolan L (2013): Non-communicable diseases and youth a critical window of opportunity for Latin America and the Caribbean Population Reference Bureau, Policy Brief

7. Meader N, King K, Moe-Byrne $\mathrm{T}$, Wright H, Graham HM,Petticrew M, Power C, White $\mathrm{M}$ andSowden AJ (2016): A systematic review on the clustering and co-occurrence of multiple risk behaviors. BMC Public Health, 16:657.DOI10.1186/s12889-016
8. Roushdy R. and Sieverding M (2015): Panel Survey of Young People in Egypt: Generating Evidence for Policy and Programs. Cairo, Egypt: Population Council.www.popcouncil.org

9. Anísio Luiz da Silva Britoa, Carla Meneses Hardmanb, Mauro Virgílio Gomes de Barros (2015): Prevalence and factors associated with the cooccurrence of health risk behaviors in adolescents. Rev Paul Pediatr. 2015;33(4):423-430

10. Dumith S C. Muniz L C. Tassitano R M, Hallal P C, and Menezes AM.B (2012): Clustering of risk factors for chronic diseases among adolescents from Southern Brazil. Prev Med; 54(6): 393-396.

doi:

10.1016/j.ypmed.2012.03.014

11. Kontis V, Mathers C D, Bonita R, Stevens G A (2015): Regional contributions of six preventable risk factors to achieving the $25 \times 25$ noncommunicable disease mortality reduction target: a modeling study. Lancet Glob Health; 3: e746-57.

12. Adhikari $\mathrm{K}$ and Adak $\mathrm{M} \mathrm{R}$. (2012): Behavioral risk factors of noncommunicable diseases among adolescents. Journal of Institute of Medicine, December, 2012; 34:3 3943www.jiom.com.np

13. Talat $\mathrm{M}$ A and, El Shahat E (2015): Prevalence of overweight and obesity among preparatory school adolescents in Urban Sharkia Governorate, Egypt- Egyptian Pediatric Association Gazette ,journal homepage: tttp://www.elsevier.com/locate/epag ).

14. Silva DAS, Peres KG, Boing AF, González-ChicaDA, PeresMA (2013): Clustering of risk behaviors for Chronic non-communicable diseases: a population-based study in southern Brazil. Prev Med 56:20-24.doi: 10.1016/j.ypmed.2012.10.022 PMID: 23123860

15. Zaman MM, Bhuiyan MR, Karim N.Zaman M, Rahman M, Akanda A and 
Fernando T (2015): Clustering of noncommunicable diseases risk factors in Bangladeshi adults: An analysis of STEPS survey2013. BMC Public Health (2015) 15:659. DOI10.1186/s12889-0151938-4

16. Salameha $\mathrm{P}$, Jomaab L, Issac C, Farhat G,Zeghondi H, N.Gerges c, M.T.Sabbaghb,c, M.Chaayad, B.Barbour c, M.Wakede, J. Salame 'f N. SaadallahZeidanc and I. Bald (2014): Assessment of health risk behaviors among university students: a cross-sectional study in Lebanon. Int. Journal of Adol. \&Youth, 19 (2): 203-216.

17. Laxer Rachel E., Ross C. Brownson, Joel A. Dubin, Martin Cooke, Ashok Chaurasia1 and Scott T.Leatherdale1 (2017): Clustering of risk-related modifiable Behaviors and their association with overweight and obesity among a large Sample of youth in the COMPASS study BMC Public Health, 17:102.

18. Pengpid S, Peltzer K, Kassean HK, Tsala JPT, Sychareun V, FalkMu (2015): Physical inactivity and associated factors among university students in 23 low, middle and high income countries. Int J Public Health (2015) 60:539-549

19. WHO (2016): Adolescents: health risks and solutions, Fact sheet Updated May 2016

20. Hallal PC. Andersent B. Bull FC, GutholdR, Haskell W and Ekelund U (2012): Lancet physical activity series working group, Global physical activity levels: surveillance progress, pitfalls and prospects.. Lancet, 380 (9838: 247-257). 21. Survey of Young People in Egypt (SYPE) (2009): Time use. December
2010, The Population Council, Inc. | www. popcouncil.org

22. Haregu TN, Oti S, Egondi T and Kyobutungi C (2015): Co-occurrence of behavioral risk factors of common noncommunicable diseases among urban slum Dwellers in Nairobi, Kenya. Global Health Action 2015, 8:28697http://dx.doi.org/10.3402/gha.v8.28697

23. Liu Y, Croft JB, Wheaton AG, Kanny D, Cunningham TJ, Lu H (2016): Clustering of Five Health-Related Behaviors for Chronic Disease Prevention Among Adults،United States, 2013. Prev Chronic Dis; 13: 160054. DOI:http://dx.doi.org/10.5888/pcd13.160 054.

24. Coups EJ, Gaba A, Orleans CT (2004): Physician screening for multiple behavioral health risk factors. Am J Prev Med 27: 34-41. PMID: 15275672

25. Schuit A J, vanLoon AJM, TijhuisM, Ocke' MC (2002): Clustering of life style risk factors in a general Adult population. Prev Med 35: 219 224. PMID: 12202063

26. Silva DAS, Peres KG, Boing AF, González-ChicaDA, PeresMA (2013): Clustering of risk behaviors for Chronic non-communicable diseases: a population-based study in southern Brazil. Prev Med 56:20-24.doi: 10.1016/j.ypmed.2012.10.022 PMID: 23123860

27. Poortinga W (2007): The prevalence and clustering of four major lifestyle risk factors in an English adult population. PrevMed44:124-128.PMID: 17157369 